\title{
CAMELLONES E AGRICULTURA PRÉ-HISPÂNICA NA SABANA DE BOGOTÁ-COLÔMBIA: UM EXEMPLO DE GESTÃo DA ÁGUA EM ÁREAS INUNDÁVEIS
}

\author{
LORENA RODRÍGUEZ-GALLO ${ }^{(1)}$
}

Resumo:

O objetivo central do presente artigo foi o de analisar o sistema hidráulico de campos elevados de cultivo, camellones, construído ao longo de 2500 anos por populações pré-hispânicos da Sabana de Bogotá, Colômbia. A análise focou a relação estabelecida entre estas populações e a água, de modo a explicar os mecanismos pelos quais essa interação levou à construção duma paisagem agrícola, em particular no que diz respeito ao aproveitamento de recursos e de ocupação do território, durante o período Muisca Tardío (1000-1550 DC). A discussão baseou-se na perspectiva teórica da arqueologia da paisagem e esteve apoiada na metodologia da fotointerpretação bem como na análise de dados arqueológicos, paleo-ambientais e de documentação colonial, conseguindo assim concluir que o sistema de camellones foi o resultado da inter-relação homem-meio, pela qual as populações pré-hispânicas criaram uma forma de viver num meio alagado, fazendo da água o eixo e a rede de ligação entre os canais, plataformas para 0 cultivo, assentamentos, áreas de caça, de pesca e de mitigação das enchentes.

Palavras-chave: Camellones, Muiscas, Sabana de Bogotá, agricultura pré-hispânica, arqueologia da paisagem

Abstract:

\begin{abstract}
Camellones and pre-hispanic agriculture in the Sabana de Bogotá-Colombia: an example of water management in flooded areas

The central theme of this article is the hydraulic system of raised fields, camellones, built throughout 2,500 years by the Prehispanic populations of the Sabana de Bogotá, Colombia. The analysis focused on the relationship established between these populations and water, in order to explain the mechanisms by which this interaction led to the construction of an agricultural landscape, in particular regarding the use of resources and the occupation of the territory, during the Late Muisca period (1000-1550 AD). The discussion was based on the theoretical perspective of landscape archeology and was supported by the methodology of photointerpretation as well as the analysis of archaeological, paleoenvironmental and colonial documentation data, thus concluding that the camellones system was the result of interrelationship man-environment, whereby the Pre-Hispanic populations created a way of living in a flooded environment, making water the axis and the network of connection between channels, cultivation platforms, settlements, hunting, fishing and flood mitigation areas
\end{abstract}

Keywords: Raised-fields, Muiscas, Sabana of Bogotá, prehispanic agriculture, landscape archaeology

\section{INTRODUCC̃̃O}

O que fazer com a água quando ela é abundante e dificulta o quotidiano dum grupo humano? Esta foi a pergunta que guiou a investigação relativamente aos grupos préhispânicos da Sabana de Bogotá, os quais habitaram um território alagadiço que foi em tempos o lar dum lago pleistocênico. Neste artigo apresenta-se uma resposta a esta questão, a qual é produto de uma análise na ótica da arqueologia da paisagem e, portanto, que teve em conta os vários fatores, ecológicos e humanos, que incidiram na construção de uma paisagem particular.

O objetivo do presente trabalho é examinar como as antigas populações da Sabana de Bogotá encararam o problema de habitarem num meio ecológico de planície com grande presença da água. Os trabalhos feitos até agora (BROADBENT 1968; BERNAL 1990; ETAYO 2002; KRUSCHEK 2003;
BOADA 2006) centraram-se na reconstrução e análise morfológica do sistema, na descrição das características fisiográficas da Sabana e na relação entre organização social e produtividade dos camellones. No presente artigo, pretende-se discutir o sistema hidráulico desde uma perspectiva mais abrangente que não foque apenas os aspectos técnicos e a sua capacidade produtiva, mas também que analise a complexa relação estabelecida entre o homem e o meio ecológico que esse sistema revela. Com a construção de um sistema de cultivo em uma área inundável, não só se procurou controlar a água, mas também construir uma paisagem que integrasse a água no quotidiano económico, social e cultural das populações pré-hispânicas da Sabana. Não se procurou somente estabelecer a sua funcionalidade e a sua efetividade, mas também descobrir como estas populações se relacionaram com a água para partilhar com ela o mesmo espaço onde viveram, cultivaram e desenvolveram as suas atividades quotidianas. 


\section{CONTEXTO}

A Sabana de Bogotá está inserida numa unidade geográfica maior, o Planalto Cundiboyacense, localizado a 2.600 metros de altitude, na Cordilheira Oriental do sistema andino colombiano (Fig. 1). Em termos geológicos, a Cordilheira Oriental é de formação recente, culminando a sua ascensão há 3.5 milhões de anos (PÉREZ PRECIADO 2000: 4,5). Resultado deste soerguimento foi a formação duma fossa (futura Sabana de Bogotá) onde ficaram presas as abundantes águas que desciam das montanhas em seu redor, formando um extenso lago. Porém, mudanças climáticas com fortes precipitações que tiveram lugar entre 50.000 AP e 35.000 AP, erodiram o único vale de drenagem que possuía a Sabana, seguindo-se uma seca entre 30.000 AP e $28.000 \mathrm{AP}$, culminando na dessecação do lago entre 32.000 AP e 27.000 AP (VAN DER HAMMEN 1992: 183).

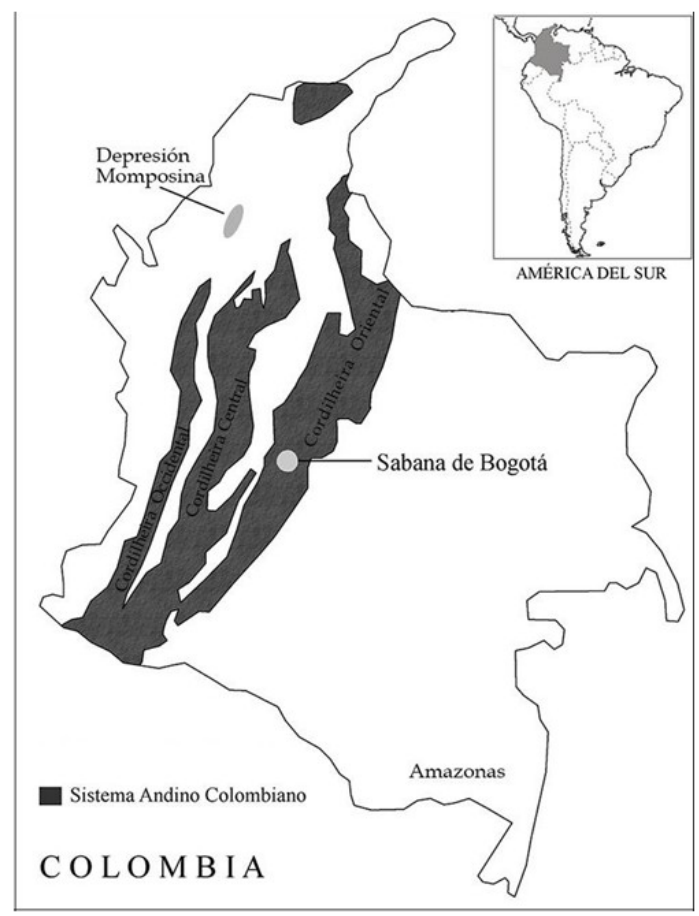

Fig. 1. Área de estudo.

Fig. 1. Area of study.

Em consequência disso, formou-se uma planície com solos argilosos de formação fluviolacustre com encharcamentos sazonais, áreas de inundação permanente e levemente inclinada nas direções norte- centro, sul-centro, leste-oeste, que fariam do vale médio do Rio Bogotá o setor mais baixo e inundável da Sabana (ETAYO 2002). Este ambiente inundável seria alimentado pelos vários rios que continuaram a descer das montanhas em redor e que alimentaram o único vale de drenagem da planície: o Rio Bogotá (Fig. 2).
Foi este o território que começou a ser povoado por grupos humanos desde $12.400 \mathrm{AP}$ (CORREAL et al. 1969: 16), provenientes das terras baixas da Amazônia e dos vales interandinos (CORREAL \& VAN DER HAMMEN 1992: 220; RoDRIGUEZ CUENCA 1999). Lentamente, o espaço foi sendo ocupado, primeiro colonizando-se os abrigos rochosos, local seguro contra as intempéries e a água, depois, por volta dos anos $7.800 \mathrm{AP}$ a $5.000 \mathrm{AP}$, por meio de acampamentos a céu aberto, em terraços bem localizados que garantiam a segurança em relação às áreas alagadas, mas com acesso direto aos recursos lacustres (ARDILA 1984; GROOT 1992; ORRANTÍA 1997).

Finalmente, quando chegamos à primeira fase agrícola (Período Herrera) assiste-se à ocupação geral de toda a Sabana, mesmo nos vales de inundação (BERNAL 1990; KRUSCHEK 2003; BOADA 2006). Estes grupos de agricultores (Herreras e, mais tarde, Muiscas) foram complexificando as suas atividades económicas e a sua organização social, acabando por se desenvolver uma sociedade de cacicados com hierarquias definidas, uma elite político-religiosa, um sistema tributário organizado e uma economia baseada em atividades como a ourivesaria, a tecelagem, a exploração de sal mineral e de esmeraldas e duma exploração agrícola especializada ancorada num sistema hidráulico de campos elevados de cultivo (CARDALE 1981; LANGEBAEK 1985, LleRAS 1999; BOADA 2000; GAMBOA 2008). Era esta a situação destas populações em 1526, aquando da chegada dos exércitos espanhóis ao planalto.

\section{METODOLOGIA}

De forma a reconstruir o sistema hidráulico de campos elevados de cultivo, construído pelas sociedades agrícolas pré-hispânicas da Sabana de Bogotá, utilizou-se a fotointerpretação de fotografias aéreas antigas, tiradas entre 1938 e 1956 pelo Instituto Geográfico Agustín Codazzi - IGAC (Anexo 2). Este material foi obtido por meio de 25 voos realizados a diversas escalas que variam entre 1:3.000 até 1:24.000, e em diferentes alturas do ano, o que permite múltiplas visualizações, com diferentes incidências da luz, dos vestígios arqueológicos. Também os voos feitos durante a estação das chuvas permitem identificar as atuais áreas de alagamento sazonais e a sua relação com as estruturas em terra dos camellones.

É importante esclarecer que se usou a fotointerpretação de fotografias aéreas antigas e não de outro tipo de informação como as imagens de satélite porque a maior parte do espaço onde se encontrava o sistema hidráulico está hoje coberto por quilômetros de cimento e alcatrão. A capital do 


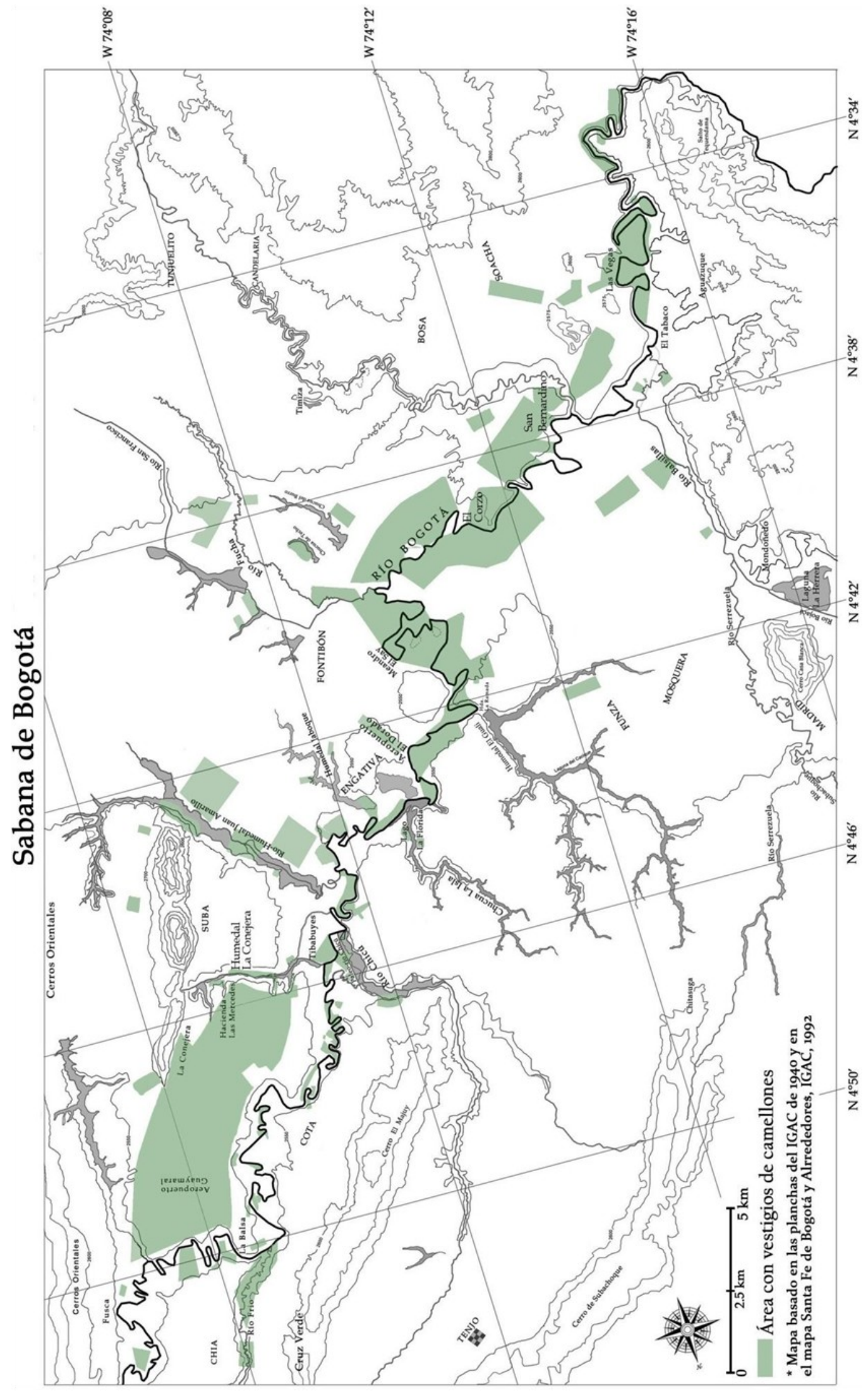

Fig. 2. Sabana de Bogotá com as áreas de camellones assinaladas. Fig. 2. Sabana de Bogotá; the areas of the camellones are marked. 
país, Bogotá, construiu-se sobre seus antigos canais sedimentados, causando, como consequência, a destruição total dos vestígios arqueológicos. Além disso, as áreas que ainda não foram destruídas têm sido fortemente transformadas pela acumulação de atividades ligadas à agroindústria e à criação de gado.

No processo de fotointerpretação foram feitos os seguintes passos:

1) Digitalização das imagens a 600 dpi.

2) Junção das fotografias pertencentes aos mesmos voos de modo a se poder obter uma imagem de conjunto.

3) Identificação e isolamento dos elementos modernos presentes nas fotografias como: estradas, vedações, prédios, marcas de arados mecânicos, canais artificiais, canalização de rios, mudanças no percurso dos rios e desativação artificial de meandros.

4) Identificação dos vestígios arqueológicos das estruturas em terra pertencentes ao sistema hidráulico antigo (Fig. 3):

a) Estabelecimento do curso dos rios no momento do abandono do sistema hidráulico: para atingir este objetivo procurou-se determinar quais dos atuais paleo-meandros tinham vestígios do sistema hidráulico, uma vez que isso significava que estavam ativos aquando do seu abandono. Também a existência de vestígios das estruturas em terra ao longo de áreas retilíneas e escuras indicava a existência dum antigo curso de água hoje inexistente. b) Estabelecimento das áreas húmidas: com o sistema hidráulico a funcionar, as inundações sazonais estavam perfeitamente controladas, o que quer dizer que nem todas as atuais áreas húmidas permanentes ou sazonais deviam existir no período pré-hispânico. Neste sentido, a existência de estruturas em terra no meio dos atuais locais de inundação sazonal ou das áreas húmidas permanentes, indicam que nestas áreas existia um sistema de controlo dos alagamentos que permitia a existência de culturas.

c) Identificação de canais e plataformas pertencentes ao sistema hidráulico préhispânico: as áreas de cultivo reconhecem-se pela cor mais clara na fotografia, produto dos processos erosivos associados às atividades agrícolas enquanto que os canais identificam-se pela cor escura. Há que salientar que a fotointerpretação também pressupõe a identificação de padrões associados às diferentes tipologias das estruturas em terra: em xadrez, lineares, irregulares e paralelos.

d) Identificação de diacronias: procurou-se identificar diferentes momentos no processo de construção do sistema hidráulico, através da análise de sobreposições das estruturas em terra. Também se identificaram paleo-meandros inativos (já na altura da última fase de funcionamento do sistema hidráulico) com vestígios do sistema hidráulico, junto de meandros ativos com vestígios dos canais e plataformas.

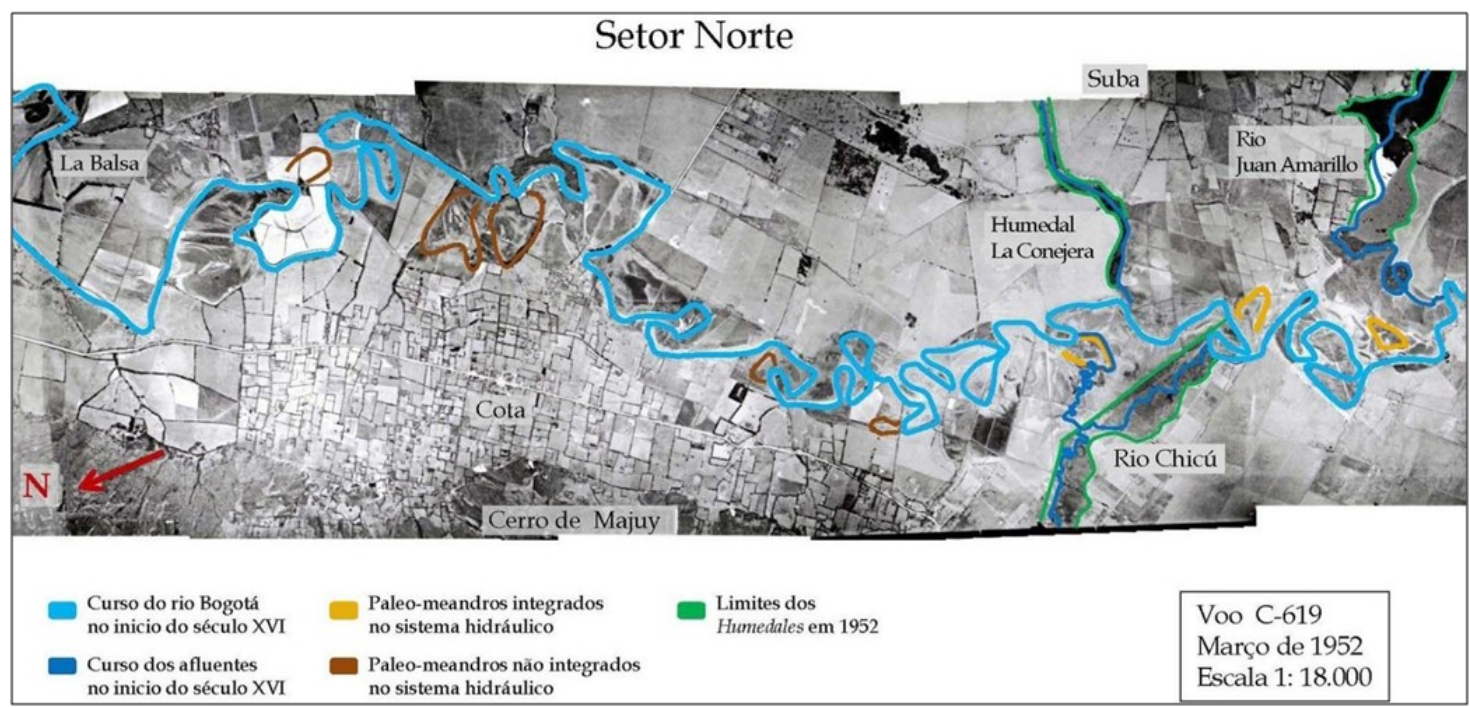

Fig. 3. Processo de fotointerpretação.

Fig. 3. Process of photointerpretation.

A fotointerpretação foi apoiada por dados obtidos em trabalhos arqueológicos na Sabana de Bogotá, especificamente aqueles relativos aos grupos das fases agrícolas: Herrera (800 a.C. - 100 d.C.), Muisca Temprano (100 d.C. - 1000 d.C.) e Muisca Tardío (1000 d.C. - 1550 d.C.) (Anexo 1) e pelos dados paleo-ambientais que permitissem reconstruir o contexto ecológico da Sabana de Bogotá nos momentos prévios à colonização e a sua transformação com a instalação dos espanhóis, os quais trouxeram consigo novas plantas, culturas e animais (VAN DER HAMMEN 1992, 2003). 
Dado que o sistema hidráulico visível nas fotografias aéreas corresponde à última fase do seu funcionamento, a sua análise restringe-se ao período Muisca Tardío (1000 d.C. - 1550 d.C.). Porém, note-se que também se tomaram em conta os dados arqueológicos de toda a fase agrícola (Herrera e Muisca Temprano) a fim de ajudar na compreensão do processo de ocupação e transformação da paisagem agrícola pré-hispânica da Sabana de Bogotá.

\section{OS CAMELLONES E A CONSTRUÇÃO DA PAISAGEM AGRÍCOLA PRÉ- HISPÂNICA}

O objetivo fundamental dos sistemas hidráulicos de campos elevados de cultivo, ou camellones, como são conhecidos na América hispânica, foi o de drenar o excesso de água nas áreas de inundação, permanentes ou sazonais. Com algumas diferenças, sistemas de este tipo foram construídos pelas sociedades agrícolas préhispânicas ao longo de todo o continente americano, tanto em ambientes de montanha como em terras baixas tropicais (Fig. 4). Vestígios da sua existência podem encontrar-se ainda no Vale do México, no Lago Titicaca, em Guayas e outras zonas costeiras do Equador, nas planícies da Venezuela ou na região amazônica da Bolívia só para mencionar alguns exemplos (PARSONS 1969; HAMMOND 1984; ERICKSON 1988A, 1988B, 1993; GASSÓN 1998; DELGADO-ESPINOZA 2002; VALDEZ 2006). Na Colômbia também foram construídas estas estruturas. Até agora foram identificados e analisados vestígios dum sistema hidráulico na "Depressão Momposina" nas terras baixas do norte do país (PARSONS \& Bowen, 1966; PlazAs et al., 1993) e na Sabana de Bogotá (BROADBENT 1968; BERNAL 1990; BOADA 2006; RODRÍGUEZ-GALLO 2011), objeto da nossa presente análise.

Os camellones são estruturas feitas em terra

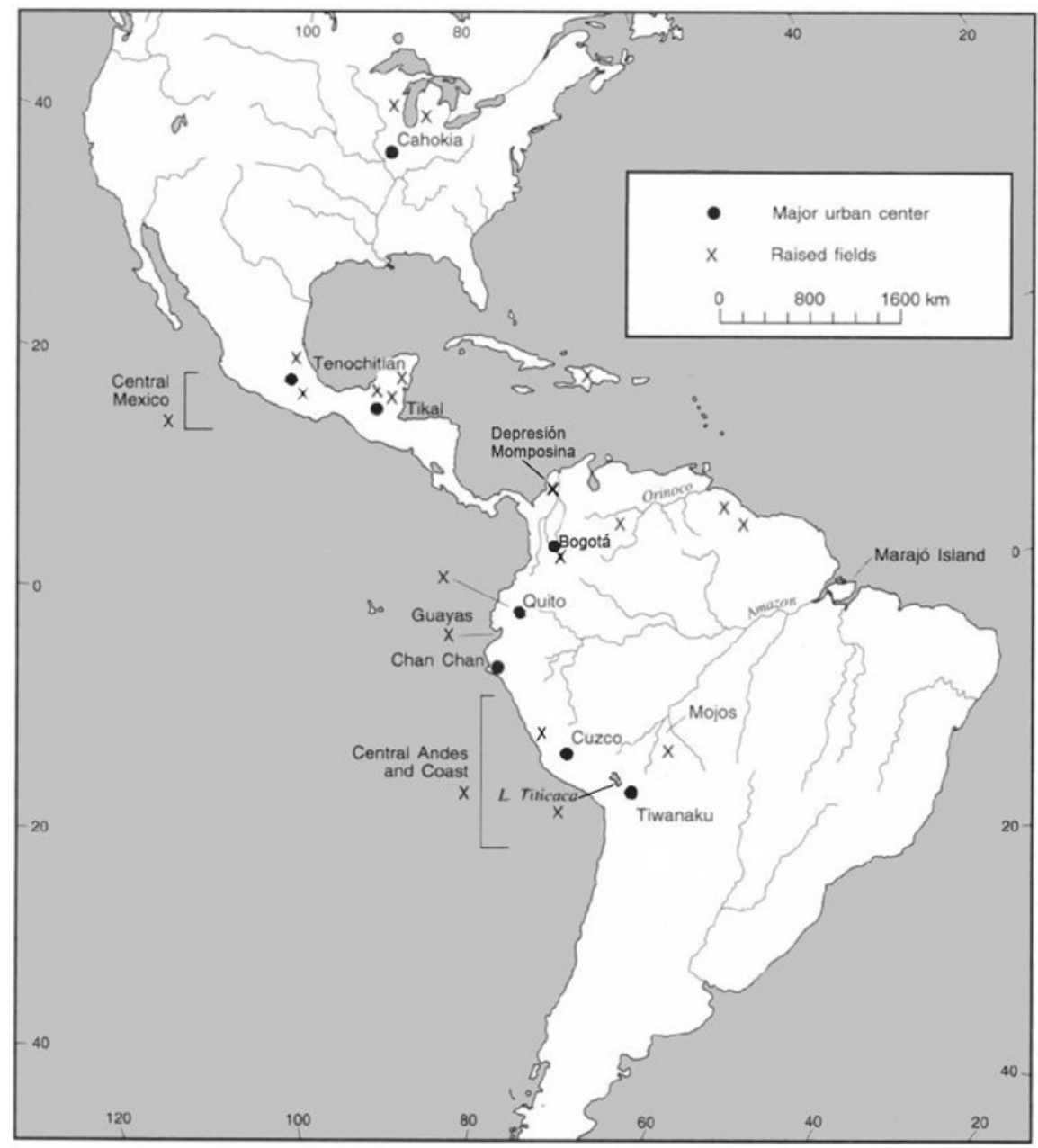

Fig. 4. Localização dos sistemas hidráulicos de cultivo pré-hispânicos na América. Adaptado de Denevan, 1992.

Fig. 4. Location of Prehispanic hydraulic systems in America. Adapted from Denevan, 1992. 
(sem muros de contenção em pedra), construídas em áreas de inundação permanente e sazonal, integradas por canais de drenagem intercalados com plataformas elevadas e feitas com a terra residual do traçado dos canais. As plataformas tinham uma altura média de $70-90 \mathrm{~cm}$ em relação ao solo e foram construídas com o intuito de manter secas as raízes das plantas bem como para evitar que as culturas fossem afetadas nos períodos de maior alagamento (Fig. 5).

Através dos canais, a água distribuía-se de forma controlada ao longo da planície durante o inverno. $\mathrm{Na}$ estação seca poderiam ser utilizados como reservas de água, quer retendo-a por meio do uso de diques, quer aproveitando a ligeira inclinação da planície, contribuindo assim para manter a terra húmida, garantindo desta forma uma boa colheita.

Assim, o sistema hidráulico permitia não só cultivar em áreas de inundação, que inicialmente não eram aptas para a agricultura, mas também tinha a vantagem de aumentar a sua produtividade relativamente aos cultivos tradicionais: o material orgânico acumulado nos canais durante as cheias era posteriormente retirado e depositado sobre as plataformas, acrescentando-se assim importantes nutrientes às culturas. Os camellones também foram um sistema de cultivo muito apropriado para o contexto andino porque ajudavam a resolver um problema que ainda hoje afeta os camponeses destas terras altas: as geadas, que fazem com que as plantas se queimem. Este processo acontece nos meses mais quentes do ano (dezembro-fevereiro/ junho-agosto) em que aumenta a amplitude térmica diária, passando dos $5^{\circ} \mathrm{C}$ negativos ao alvorecer até aos $22^{\circ} \mathrm{C}$ durante a tarde. $\mathrm{O}$ sistema hidráulico neutralizava este efeito, já que a água presente nos canais aquecia durante o dia, mantendo morna a terra durante a noite, evitando que as quedas de temperatura afetassem as culturas. $\mathrm{O}$ tamanho e a morfologia dos canais e plataformas variavam de acordo com o nível de inclinação da planície, o volume de água a controlar, as características do solo e a própria morfologia do rio. Assim, podemos encontrar sistemas de canais em forma de "espinha de peixe" ou em forma de "trança" (Depresión Momposina, norte da Colômbia), em xadrez (Lago Titicaca, BoliviaPerú, e Llano de Mojos, Bolivia) ou "flutuantes" (México) (Fig.6).

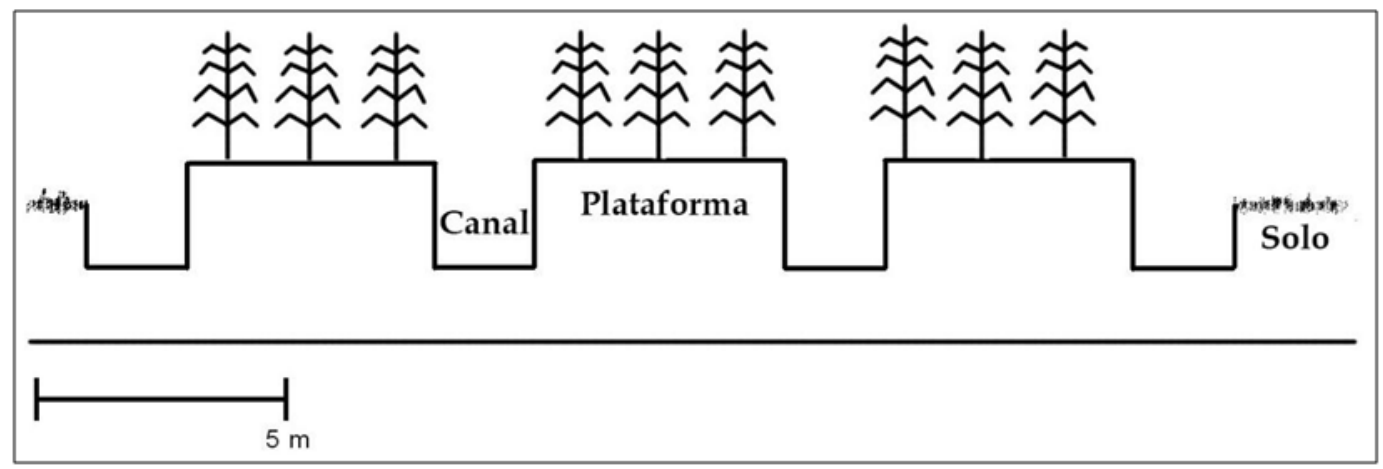

Fig. 5. Desenho esquemático dos camellones.

Fig. 5. Schematic drawing of the camellones.

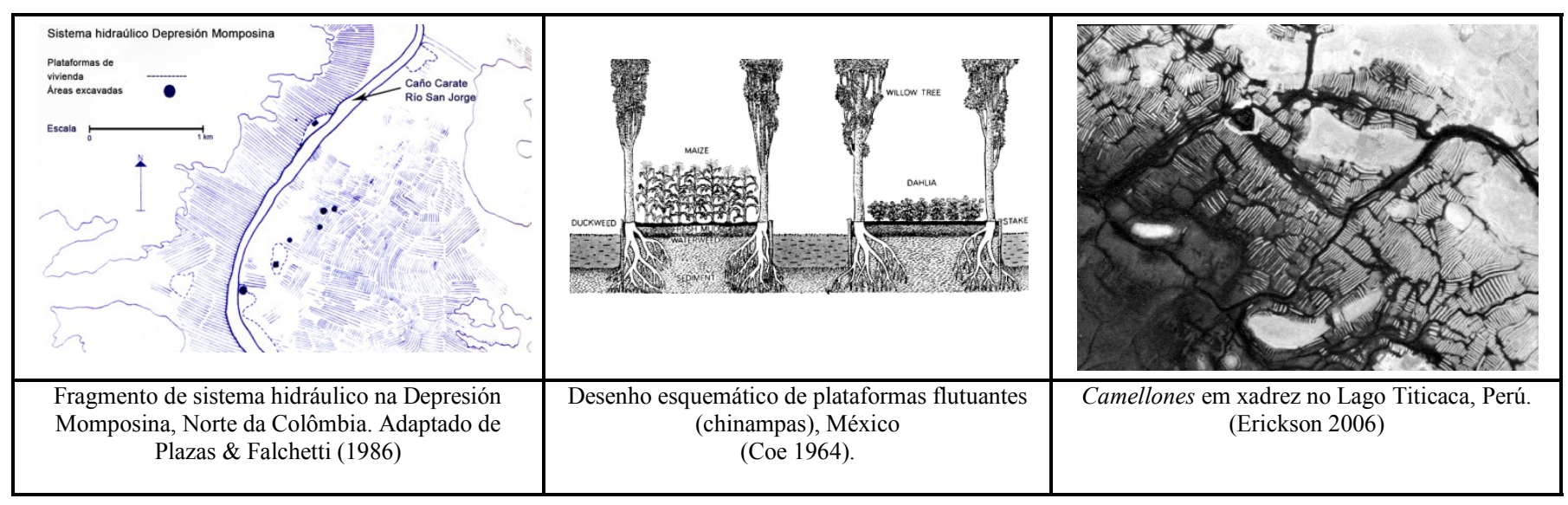

Fig. 6. Exemplos de camellones construídos pelos grupos pré-hispânicos na América.

Fig. 6. Examples of camellones built by Prehispanic groups in America. 
O eixo do sistema hidráulico da Sabana era o Rio Bogotá que a atravessa no sentido sudestenoroeste. Ao longo deste rio e dos seus afluentes construiu-se uma série de canais e plataformas elevadas para a agricultura. Segundo datações por C14, a construção do sistema hidráulico teria começado cerca de $1320+/-40$ a.C. (C14 calb) (Boada 2006) e teria funcionado até a altura da colonização espanhola, cobrindo uma área de mais de 15.800 hectares, segundo a fotointerpretação arqueológica realizada por Boada (2006) e Rodríguez-Gallo (2011), a partir das fotografias aéreas tiradas pelo Instituto Geográfico Agustín Codazzi (IGAC), entre os anos 1938 e 1956.

Em termos da morfologia, os camellones da Sabana têm quatro tipos de estruturas: canais lineares, camellones paralelos, irregulares e em xadrez (Figs. $7 \mathrm{a}, 7 \mathrm{~b}$ y $7 \mathrm{c}$. $)^{1}$. Os canais, perpendiculares ao rio Bogotá e alguns dos seus afluentes, podiam atingir 1 $\mathrm{km}$ de comprimento por $12 \mathrm{~m}$ de largura nas áreas mais baixas da Sabana e a sua principal função era a de controlar rapidamente os grandes volumes de água na estação chuvosa, mantendo-a nos próprios canais ou dirigindo-a para o interior da planície.

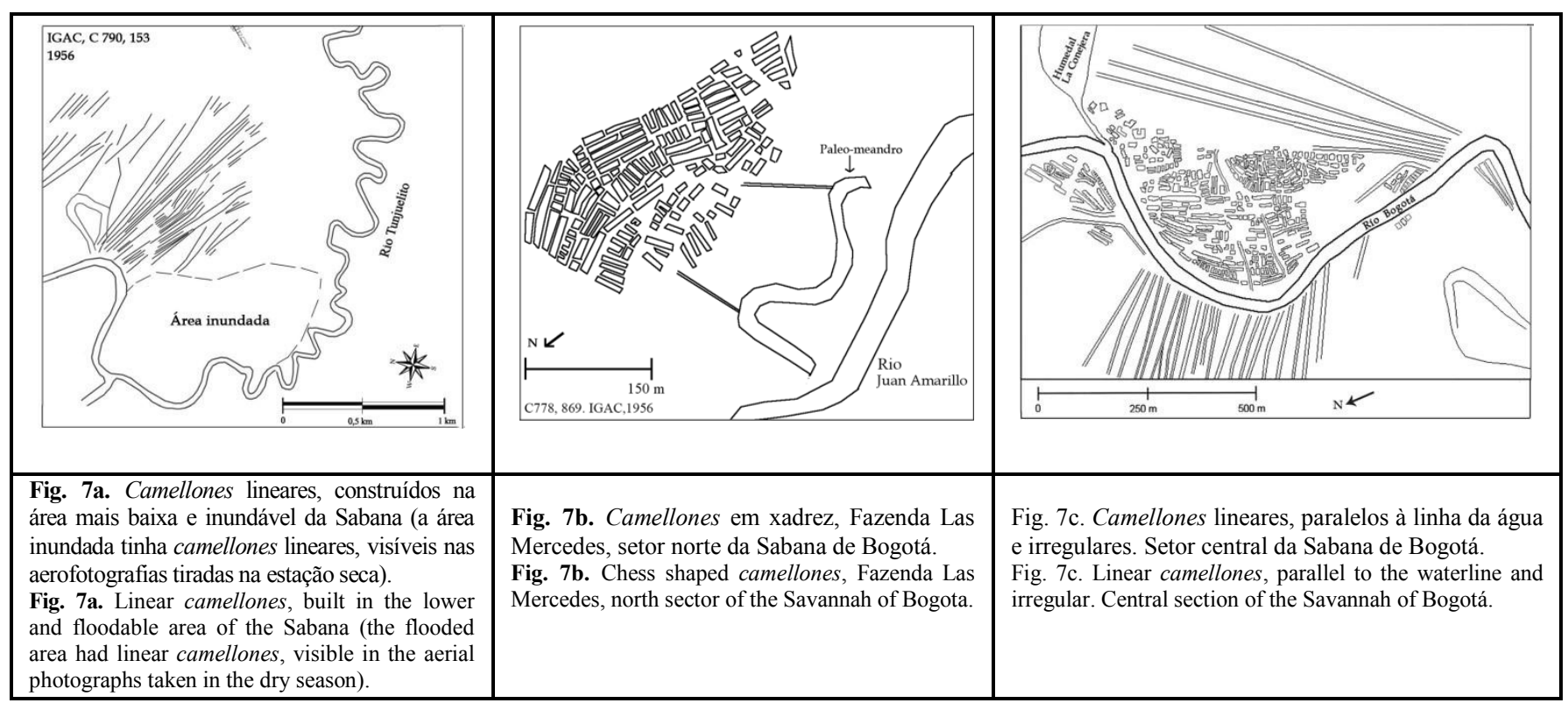

Os camellones em xadrez são conjuntos de três a dez plataformas de $20 \mathrm{~m}$ a $50 \mathrm{~m}$ de comprimento por $2 \mathrm{~m}$ a $5 \mathrm{~m}$ de largura, intercaladas por canais de $50 \mathrm{~cm}$ a $2 \mathrm{~m}$ de largura, em média. Cada conjunto de plataformas tinha uma orientação diferente (similar a um tabuleiro de xadrez) e estava separado dos outros por pequenos canais. Foram construídos no interior da planície, onde os encharcamentos eram produzidos pelo alto nível do lençol freático. Esta é a razão pela qual não existem grandes canais de drenagem em redor. A extraordinária fossilização da paisagem no setor Guaymaral-La Conejera-Las Mercedes, no norte da Sabana, permitiu reconstruir detalhadamente este tipo de plataformas. É muito provável que este tipo de camellones também se espalhasse pelas planícies de Cota, Chia, Suba, Engativá, Funza e Soacha, a julgar por alguns vestígios identificados nestes setores (ver RODRÍGUEZ-GALLO 2015).

Os camellones paralelos predominam ao longo da várzea do rio Bogotá. A sua construção baseou-se no aproveitamento das barras de sedimentação que a migração dos meandros ia deixando, as quais foram adaptadas como plataformas para as culturas. O seu tamanho poderia variar de acordo com a amplitude da curvatura dos meandros.

No caso dos camellones irregulares, estes não parecem ter, à primeira vista, um padrão morfológico definido. Encontram-se distribuídos aleatoriamente na planície de inundação, às vezes isolados, às vezes em pequenos grupos, sem canais de drenagem em torno deles e com formas bastante variadas. Do nosso ponto de vista, esse aparente caos resulta da destruição parcial do sistema hidráulico e não porque corresponda a um certo padrão de construção, já que, ao estar localizado na planície de inundação, ficou exposto nos últimos séculos às inundações e aos processos constantes de sedimentação. No entanto, o fato de serem construídos ao longo da várzea do Rio Bogotá (de Chia até Soacha) mostra que o sistema hidráulico manteve essas culturas fora do alcance da água, dirigindo a água para áreas de mitigação (RODRÍGUEZ-GALLO 2015). A evidência arqueológica também confirma o controlo das inundações já que foram identificados assentamentos 
na planície de inundação (Kruschek 2003; Boada 2006) e não apenas em terraços à beira dos rios ou no interior da planície.

A partir da reconstrução e análise dos vestígios do sistema hidráulico propomos que a gestão da água e a distribuição das culturas tinham características diferentes conforme as áreas geográficas da Sabana.

Assim, o norte da Sabana (Chía, Cota, Usaquén, Suba) estaria dedicado fundamentalmente às tarefas agrícolas. Nesta área, a várzea é estreita e as culturas localizam-se num terraço por cima do nível do rio, pelo que o excesso de água tinha a sua origem no alto nível do lençol freático e não tanto por transbordamento. Por isso, os camellones que predominam são em xadrez e, de fato, encontram-se em grandes densidades $\left(32 \mathrm{~km}^{2}\right.$ do sistema hidráulico foram identificados). Este forte dinamismo agrícola condiz com o aumento da população registado tanto do Herrera para o Muisca Temprano como do Muisca Temprano para o Muisca Tardío (BOADA 2006).
A fotointerpretação desta área identificou poucos paleo-meandros (Fig. 3), alguns deles ainda de origem pré-hispânico, já que estão em articulação com o resto do sistema hidráulico: os camellones seguem a linha da água destes antigos meandros e continuam na linha do atual curso do rio sem quaisquer perturbações. A relativa imobilidade do rio, que testemunha a presença e ação do sistema hidráulico, nota-se na morfologia dos paleomeandros já que não se observaram migrações progressivas ou evidentes mudanças no curso do rio.

Os poucos canais lineares para drenagem concentram-se nos meandros de Tibabuyes-Chicú (podem atingir $600 \mathrm{~m}$ de comprimento) o que indica que esta era uma zona crítica para os transvasamentos (Fig. 8). De fato, aqui a várzea alarga-se. Os excessos de água deviam ser dirigidos para o interior da planície ou para pontos específicos da várzea (áreas de mitigação) $)^{2}$, alagando-as de forma intencional, mas ao mesmo tempo minimizando o seu impacto sobre as culturas nos períodos de maior precipitação.

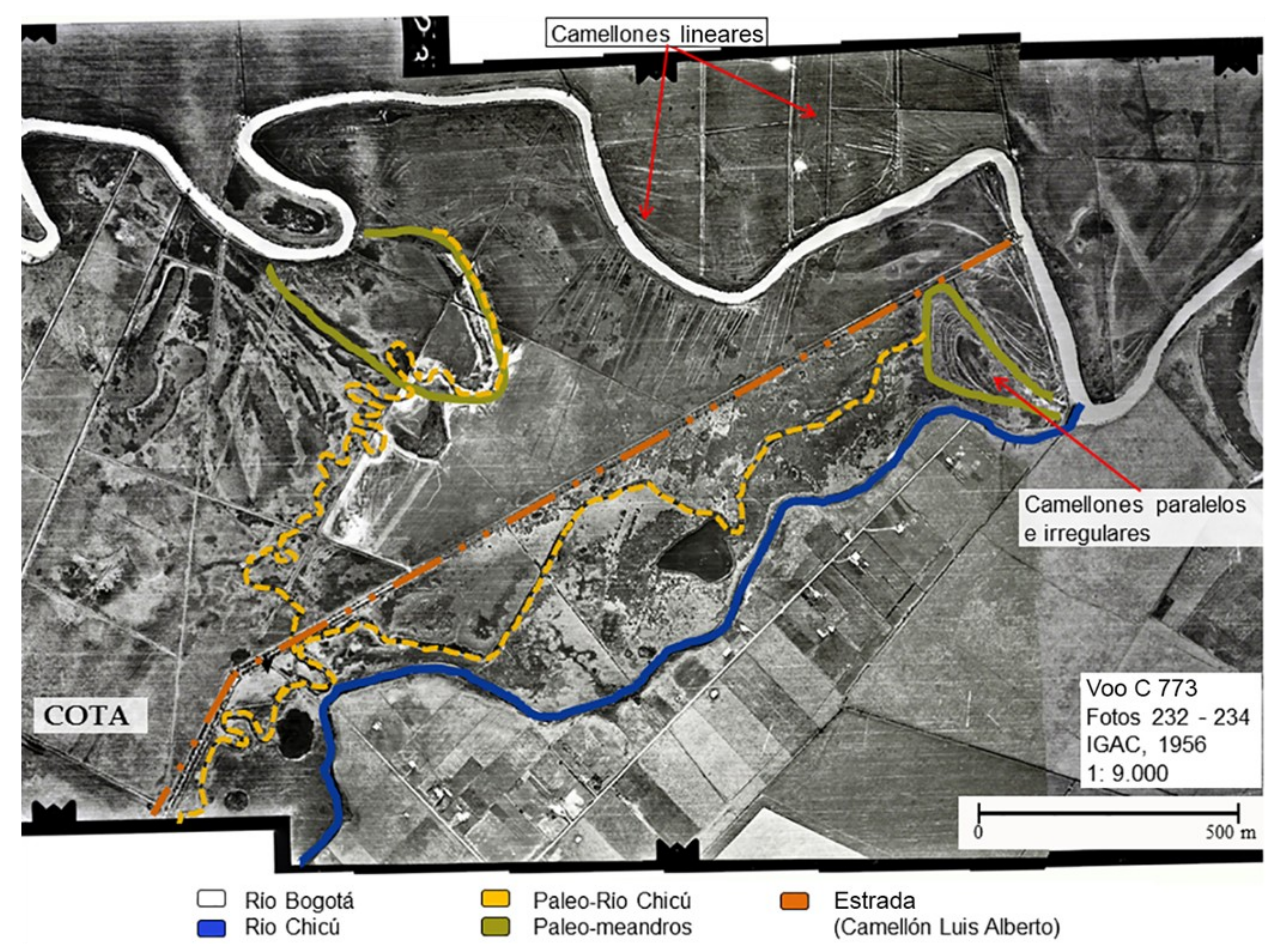

Fig. 8. Fotointerpretação no Setor Norte do Rio Bogotá, Cota.

Fig. 8. Photointerpretation in the Northern Sector of the Bogotá River, Cota.

As zonas húmidas de La Conejera e Juan Amarillo deviam ser nesta altura vales erosivos. Embora a área à sua volta se pudesse alagar, tal não chegava a afetar os cultivos porque os camellones em xadrez deviam controlar a água.
Nas fotografias aéreas (Fig. 9) são visíveis camellones no meio da água, mostrando que a inundação permanente que hoje se regista é posterior ao desabamento do sistema hidráulico. O Rio Chicú também mudou a sua morfologia. $\mathrm{Na}$

\footnotetext{
${ }^{2}$ As áreas de mitigação definem-se como áreas para onde as comunidades pré-hispânicas dirigiam a água nas épocas de chuva excessiva, inundando-as propositadamente para diminuir a energia e força da água, evitando assim destruir as plataformas de cultivo ou os canais, tendo em conta que se trata apenas de estruturas em terra sem muros de contenção sólidos. Estas áreas de mitigação foram definidas a partir da inexistência de camellones o qualquer vestígio arqueológico ou noticia colonial de existirem povoamentos na área (Rodríguez-Gallo 2015)
} 


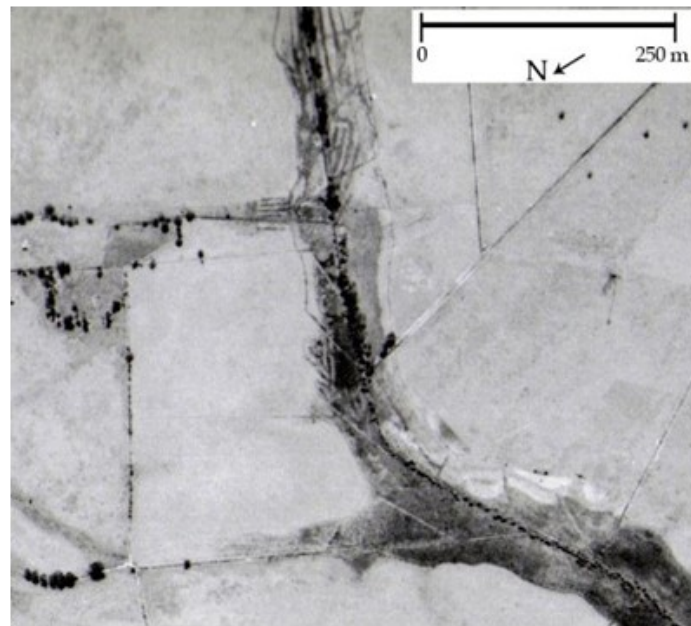

Fig. 9. Humedal La Conejera. São visíveis camellones em xadrez no meio da água, o que indica que esta zona húmida não existia na altura da existência do sistema hidráulico.

Fig. 9. Humedal La Conejera. Chess shaped camellones are visible in the middle of the water, which indicates that this wetland did not exist at the time of the existence of the hydraulic system.

figura 8 observa-se à esquerda do rio um paleo-rio que se bifurca, desembocando em dois paleomeandros do Rio Bogotá. Consideramos que esse paleo-rio corresponde ao curso original do Rio Chicú, porque no seu bordo a fotointerpretação permitiu identificar camellones em xadrez. Aliás, o atual Rio Chicú tem uma forma mais linear e sem evidências de crescimento ou migração de meandros, algo que é característico dos rios jovens.

$\mathrm{Na}$ área central (Engativá, Funza, Fontibón), no setor do Rio Juan Amarillo, a várzea do Rio Bogotá alarga, algo que coincide com a morfologia do sistema hidráulico. A presença de canais lineares aumenta, especialmente de ambos os lados do meandro El Say (Fig. 10). Entre o setor de La Florida e de El Guali observamos uma média de dez canais por cada $150 \mathrm{~m}$, com um comprimento de $800 \mathrm{~m} \mathrm{a} 900 \mathrm{~m}$ (Fig. 7c). Porém, a fotointerpretação mostra que os trabalhos modernos no solo destruíram parte dos canais, pelo que é expectável que o seu comprimento fosse maior. A efetividade destes canais na gestão da água evidencia-se na reduzida movimentação do rio, que apresenta poucos casos de crescimento e estrangulamento dos meandros.

Também na área central, a fotointerpretação evidenciou uma maior destruição dos vestígios arqueológicos pelos trabalhos modernos, mas a identificação de pequenos setores ao longo de toda esta área, incluídos atuais zonas húmidas, somado ao fato de predominarem andisols, solos adequados para a agricultura (VAN DER HAMMEN 2003), indica-nos que a planície desta área devia estar preenchida de plataformas elevadas para o cultivo.

A maior parte dos vestígios preservou-se na várzea do Rio Bogotá, o que permite evidenciar que embora seja uma área completamente exposta

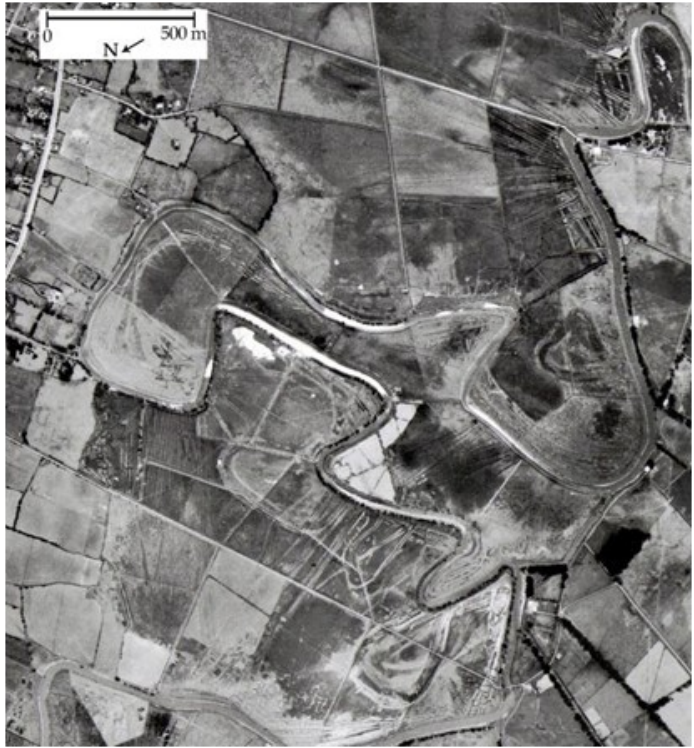

Fig. 10. Meandro El Say. Irradiando da linha de água são visíveis abundantes canais lineares. No interior do meandro encontram-se abundantes camellones paralelos e irregulares. Fig. 10. Meandro El Say. Irradiating from the water line abundant linear channels are visible. Within the meander there are abundant parallel and irregular camellones.

às inundações houve uma intensa atividade agrícola, especialmente no interior dos meandros, onde predominam os camellones paralelos ao rio. Nas partes convexas dos meandros localizam-se os canais lineares que atuavam como uma barreira de proteção, direcionando rapidamente os excessos de água para o interior da planície protegendo desta forma os camellones da várzea (ver na Fig. 7c). Estes canais lineares aumentam em densidade e tamanho à medida que nos aproximamos do centro da Sabana, o ponto mais baixo e susceptível de alagamentos sazonais.

No lado ocidental do Rio Bogotá, as evidências de cultivos também são escassas. Mais uma vez, encontramos pequenos redutos em alguns cantos, que indicam que ali havia camelllones. No Guali começa a área mais baixa da Sabana e mais suscetível a inundações. Na verdade, embora esta planície tenha presença de andisóis, existem grandes manchas de solos hidromórficos, de andisolshidromorfos e de inceptisóis-hidromorfos, devido a uma extensa rede de vales de drenagem (VAN DER HAMMEN 2003). No entanto, a abundância de material arqueológico nesta área (Funza e Mosquera) parece indicar que estava densamente povoada (GUTIERREZ \& GARCÍA 1983, 1985; BERNAL 1990; KRUSCHEK 2003; ROMANO 2003; BOADA 2006). De fato, no Rio Chicú, na zona húmida de La Florida e de El Guali e em Tibaitatá, encontram-se vestígios arqueológicos que sugerem um assentamento disperso ao longo da planície, com aldeias nucleadas à beira dos terraços naturais, ao lado do Rio Bogotá no setor de Vuelta Grande, e dentro dos braços de El Guali. 
Bernal (1990) e Kruschek (2003) também encontraram sítios arqueológicos com material do Muisca Tardio em La Ramada e El Say associados a camellones. Mas essas transformações do espaço natural não indicam que a água tenha desaparecido: foi gerida de forma a evitar prejudicar as colheitas e os assentamentos. A rede de vales erosivos de La Florida e El Guali não desapareceu; simplesmente evitou-se o seu transbordamento.

Os estudos paleoecológicos de Van der Hammen contribuíram com dados interessantes sobre os trabalhos de transformação da paisagem por parte dos grupos pré-hispânicos. Os resultados da análise de pólen de El Guali mostraram que a confluência deste antigo vale de drenagem com o Rio Bogotá foi obstruída cerca de 3.000 anos atrás, provavelmente de forma artificial, quando as atividades agrícolas na área se generalizaram. Toda a coluna de sedimento tem pólen de milho, o que indica que o vale de drenagem só foi obstruído em épocas mais recentes, permitindo a acumulação de sedimentos no seu atual leito (VAN DER HAMMEN, 2003: p. 32). A razão de tal obstrução deve ter estado associada à necessidade de controlar os alagamentos na planície de Funza, sede do principal cacicado Muisca: o Zipazgo de Bogotá. Deve ter sido tomada a opção de fechar a passagem da água do rio Bogotá para El Guali, deixando a água fluir de maneira controlada para a planície através dos canais lineares, evitando afetar as culturas e os assentamentos. $\mathrm{O}$ facto de este setor ter sido densamente povoado confirma que a boca do Guali foi assoreada para evitar transbordamento do Rio Bogotá neste ponto. Muitos dos vestígios arqueológicos estão localizados nos mesmos espaços onde foram identificados vestígios de camellones.

No setor sul o que mais se destaca é a predominância de canais lineares em ambos os lados do Rio Bogotá e na parte baixa do Rio Tunjuelito. Indubitavelmente, este setor foi dedicado principalmente ao trabalho de drenagem. Em San Bernardino, podemos encontrar canais que irradiam tanto da margem leste do Rio Bogotá como da margem norte do Rio Tunjuelito (Fig. 7a), e que atingem $2 \mathrm{~km}$ de extensão, guardando a confluência de grandes inundações. Embora em geral os canais tenham a função principal de drenar o excesso de água, foram identificados camellones alternando com os canais que irradiam do meandro de El Corzo (Fig.11). Também verificou-se que os canais de San Bernardino drenavam a água para uma pequena área de cultivo, revelando que o sistema hidráulico poderia ter, em alguns pontos específicos, a dupla função de drenagem-irrigação. Isto é possível dado que a zona sul da Sabana é mais seca, com precipitação anual não superior a $1000 \mathrm{~mm}$ (FAO 2010: p 33).

Evidenciou-se pouca presença de camellones quer na várzea quer no interior da planície. No Alto $\mathrm{e}$ Médio Tunjuelito, não se encontrou um único rastro que indicasse a presença de camellones. É provável que o sistema hidráulico não se tenha estendido para

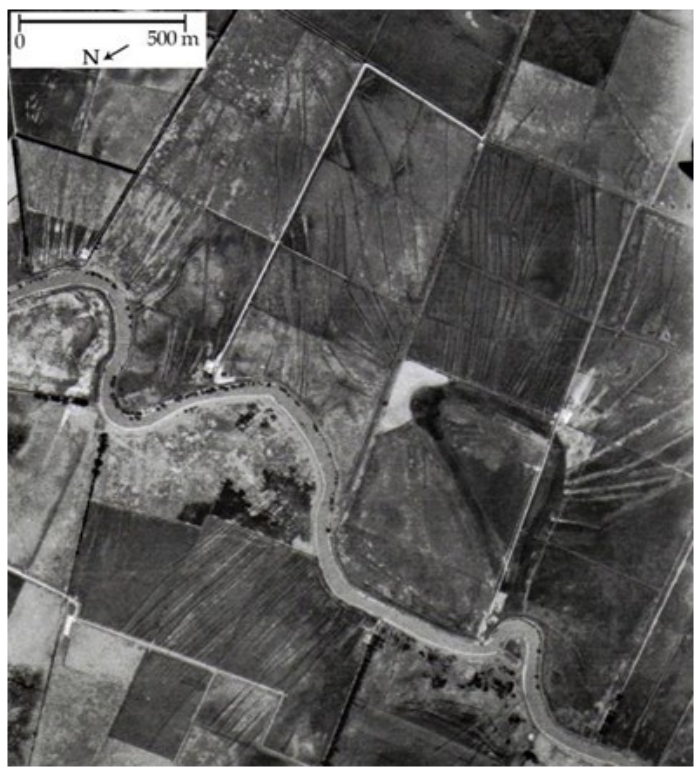

Fig. 11. Paleo-meandro com canais lineares no Setor El Corzo. Fig. 11. Paleo-meander with linear channels in the Sector El Corzo.

esta região, pois possui solos pobres para a agricultura com alto teor de argilas e presença de seixos de média e grande dimensão. Além disso, o seu leito apresenta uma forte mobilidade, com crescimento, estrangulamento e deslocamento dos meandros (Fig. 12), o que indica a ausência de um sistema de controlo de água (RODRÍGUEZ-GALLO 2011). No entanto, a evidência arqueológica

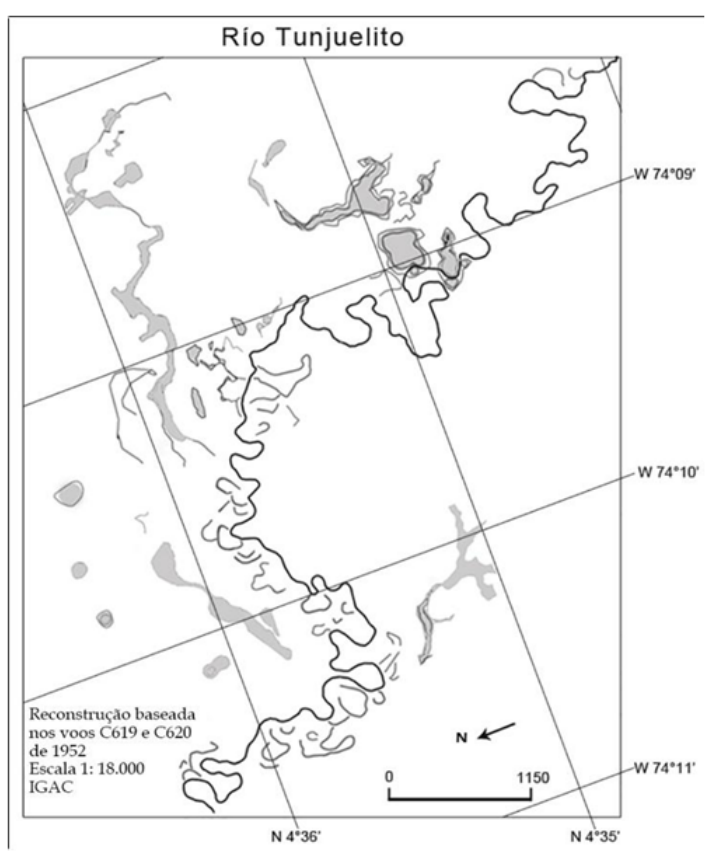

Fig. 12. Reconstrução onde é evidente a forte mobilidade que apresenta o rio Tunjuelito, o que constitui um indicador da ausência de um sistema hidráulico de controlo da água.

Fig. 12. Reconstruction where the strong mobility of the Tunjuelito River is evident, which is an indicator of the absence of a hydraulic water control system. 
mostra que esta era uma área densamente povoada, especialmente a partir do Muisca Temprano. Pelos artefatos encontrados nas diferentes escavações pode inferir-se que esta população estaria mais vocacionada para as atividades de tecelagem (SILVA 1943; Botiva 1988; MORENO \& CIFUENTES 1987; BOADA 2000; BONILLA 2005, 2008; LANGEBAEK 2012).

Este setor é importante porque a fotointerpretação permitiu identificar diacronias no processo de construção do sistema hidráulico. Nas fotografias aéreas (Fig. 13) ainda é visível um paleo-curso que de acordo com a interpretação de Etayo (2002) corresponderia a uma antiga confluência do Rio Tunjuelito com o rio Bogotá.
Porém, do nosso ponto de vista, o paleo-curso pertencia em exclusivo a um trecho do Rio Bogotá, que fluiria um pouco mais para sudeste de sua posição atual. Infelizmente, não é possível descobrir a confluência antiga através da fotointerpretação. $\mathrm{O}$ interessante é que este paleocurso tem canais de drenagem ainda visíveis, o que significa que esse trecho do rio pertencia ao sistema hidráulico e que os canais do setor de San Bernardino só foram construídos numa segunda fase, quando o Rio Bogotá fez a mudança de curso, já que a confluência atual não poderia ter existido quando o paleo-curso estava ativo, como foi destacado em uma obra anterior (RoDRÍGUEZGALLO 2011).

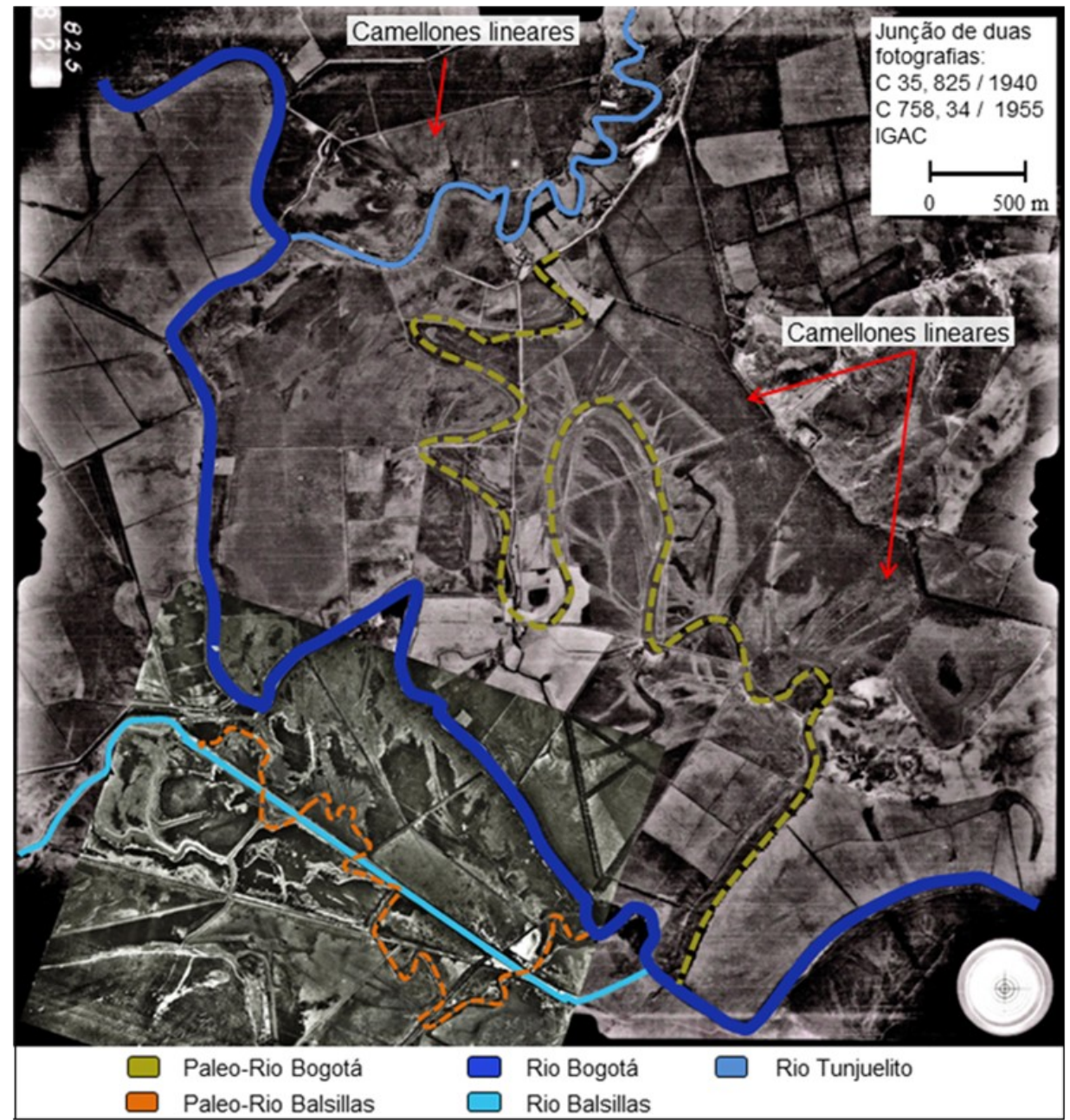

Fig. 13. Fotointerpretação do Setor Sul do rio Bogotá.

Fig. 13. Photointerpretation of the Southern Sector of the Bogotá River.

\section{CONCLUSÕES}

Podemos afirmar que a paisagem agrícola construída pelas populações pré-hispânicos da Sabana de Bogotá, foi o resultado da lenta e gradual transformação do meio natural, feito por várias gerações de pequenos grupos familiares e comunitários, com base no seu ancestral conhecimento do espaço. Assim, a Sabana de Bogotá sofreu vários momentos de profundas transformações antrópicas, que a levaram a tornarse durante a fase agrícola do período pré-hispânico num planalto coberto por canais e plataformas elevadas, onde proliferaram o milho, o feijão e os 
tubérculos. As gerações de grupos humanos que seguiram à primeira onda de povoamento que chegou 12.400 anos atrás, procedentes das terras baixas, acumularam um vasto conhecimento do ambiente ecológico que habitavam. A compreensão dessa natureza, sempre fria, sempre inundável, permitiu que a transformassem progressivamente, até conseguirem converter a sua principal dificuldade, a água, num elemento central da sua vida diária.

A análise realizada permite-nos concluir que, para o Muisca Tardio (1000 d.C. - 1550 d.C.), a paisagem da Sabana de Bogotá era constituída por um sistema de redes de canais que controlavam a água dos rios e as inundações causadas pelo alto nível do lençol freático; por plataformas elevadas de cultivo que se estendiam por toda a planície, em terraços naturais e nos vales aluviais; por áreas de mitigação para onde o excesso de água era direcionado durante o inverno; por assentamentos, nucleados ou dispersos, localizados no meio das áreas de cultivo; e por áreas de caça e pesca, localizadas em rios, zonas húmidas, lagoas e, transitoriamente, nos canais do sistema de drenagem. Esta paisagem, construída ao longo dos séculos, tornou a água uma rede de interconexão que integrava as necessidades humanas com as limitações impostas pela estrutura ecológica. Para conseguir isso, foi necessário realizar transformações fortes, como o desmatamento para permitir grandes áreas de cultivo e a obstrução dos vales erosivos para minimizar os efeitos das inundações ou a inundação sazonal de grandes áreas.

Podemos ver os Muiscas morando tanto nas encostas das colinas de Suba, Cota e Soacha como nos terraços naturais das planícies aluviais (como no caso do Rio Tunjuelito), na planície e na própria várzea do Rio Bogotá. Vários destes assentamentos estão localizados no meio dos campos de cultivo, compartilhando frequentemente o espaço com os camellones de xadrez, outras vezes com os camellones irregulares e paralelos à linha de água na planície fértil do rio Bogotá. Junto deles, grandes canais garantiam que a água mantivesse o curso desenhado por eles para evitar afetar as culturas e os assentamentos, enquanto que as zonas húmidas, sazonais ou permanentes, eram aproveitadas para desenvolver atividades como a caça e a pesca.

Embora essa forma de exploração tenha procurado favorecer os interesses das populações pré-hispânicas e do ambiente ecológico, não podemos afirmar que fosse um sistema em equilíbrio, mas contingente, sujeito a processos de transformação constantes. Inundações de grandes proporções poderiam levar à expansão de áreas de mitigação, de modo a ampliar a rede de canais existentes para assegurar um melhor controlo no futuro e reconstruir as plataformas, mas também como uma oportunidade para melhores resultados na pesca ou caça em ambientes lacustres.

\section{BIBLIOGRAFIA}

Ardila, G. 1984. Chía, un sitio precerámico en la Sabana de Bogotá. Bogotá, FIAN-Banco de la República.

BERNAL, F. 1990. Investigaciones arqueológicas en el antiguo cacicazgo de Bogotá (FunzaCundinamarca). Boletín de Arqueología, 5(3): 3146.

BoADA, A M. 2000.Variabilidad mortuoria y organización social Muisca en el sur de la Sabana de Bogotá. In: B. Enciso, M. THERriEN (Eds.), Sociedades complejas en la Sabana de Bogotá. Siglos VII al XVI D.C. Bogotá, ICANH-Ministerio de Cultura: 21-43.

BoAdA, A M. 2006. Patrones de asentamiento regional y sistemas de agricultura intensiva en Cota y Suba, Sabana de Bogotá (Colombia). Bogotá, FIANBanco de la República.

BonILLA, M. J. 2005. Programa de prospección, rescate y monitoreo para el lote de desarrollo urbanístico 2 manzana C2 urbanización. San Mateo segunda etapa, municipio de Soacha Cundinamarca. Bogotá, ICANH.

Bonilla, M. J. 2008. Proyecto Prospección, rescate y monitoreo de la manzana E3 y prospección y rescate de las manzanas $\mathrm{P} 1, \mathrm{H} 1$ y G1. Terragrande 2. Hacienda Terreros, Soacha, Cundinamarca. Bogotá, ICANH.

Botiva, A. 1988. Pérdida y rescate del Patrimonio Arqueológico Nacional. Arqueología. Revista de estudiantes de Antropología, 1(5): 3-35.

BroAdBent, S. 1961. Excavaciones en Tunjuelito: informe preliminar. Revista Colombiana de Antropología, 10: 341-346.

BROADBENT, S. 1968. A prehistoric field system in Chibcha territory, Colombia. Nawpa Pacha. Journal of Andean Archaeology, 6: 135-147.

CARdale, M. 1981. Las salinas de Zipaquirá. Su explotación indigena. Bogotá, FIAN-Banco de la República,

CoE, M. 1964. The chinampas of Mexico. Scientific American, 211 (1): 90-98.

Correal, G. 1976. Las Acacias. Un cementerio Muisca en la Sabana de Bogotá. Ethnia, 48: 3-16.

CORREAL, G. 1987. Excavaciones arqueológicas en Mosquera. Arqueología. Revista de estudiantes de antropología, 1 (3): 13-17.

Correal, G. 1990. Aguazuque: evidencias de cazadores, recolectores y plantadores en la altiplanicie de la Cordillera Oriental. Bogotá, FIAN-Banco de la República.

Correal, G.; VAn der Hammen, T. 1992. El hombre prehistórico en la Sabana de Bogotá: datos para una prehistoria ecológica. In: T. VAN DER HAMMEN,. (Ed.). Historia, ecología y vegetación. Bogotá, Banco Popular - COA: 217-232.

Correal, G.; VAn der Hammen, T. \& Lerman, J. 1969. Artefactos líticos de abrigo rocoso en el Abra. Re- 
vista colombiana de antropología, Bogotá, ICAN, 14: 9-46.

CRUMLeY, C. (Ed.) 1994. Historical Ecology: Cultural Knowledge and Changing Landscapes. School of American Research Press.

Denevan, W. 1992. The pristine myth: the landscape of the Americas in 1492. Annals of the Association of American geographes, 82 (3): 369 - 385.

Delgado-EspinOzA, F. 2002. Intensive Agriculture and Political Economy in the Yaguachi Chiefdom of the lower Guayas Basin, Coastal Ecuador. Tese de Doutoramento, University of Pittsburgh.

ERIKSON, C. 1988a. An archaeological investigation of raised field agriculture in the Lake Titicaca basin of Perú. Tese de Doutoramento, University of Illinois.

ERICKSON, C. 1988b. Raised field agriculture in the Lake Titicaca Basin. Putting Ancient Agriculture Back toWork. Expedition, 30 (3): 8-16.

ERICKSON, C. 1993. The social organization of prehispanic raised fields agriculture in the Lake Titicaca Basin. In: V. SCARBOROUGH, B. IsAaC. Research in economic anthropology. Sup. 7: Economic aspects of water management in the prehispanic new world, London, Jay Press Inc.: 369-426.

Etayo, M. 2002. Evolución Morfológica del Rio Bogotá durante la Parte Superior del Holoceno entre los municipios de Cota y Soacha (Sabana de Bogotá) y su relación con los "camellones" prehispánicos. Dissertação de Licenciatura, Universidad Nacional de Colombia.

FAO. 2010. Análisis de los sistemas de producción agrícola de las Provincias de Soacha y Sumapaz (Cundinamarca). Documento de Trabajo. Proyecto TCP/COL/3202. Bogotá, FAO. Disponível em:http://coin.fao.org/coin-static/cms/ $\mathrm{med} \mathrm{i} \mathrm{a} \mathrm{/} 5 / 1228335811221450$ / sistemas_cundinamarca.pdf. Acesso em: 15 de maio de 2015 .

GAMBOA, J. 2008. Las instituciones indígenas de gobierno en los años posteriores a la Conquista: caciques y capitanes muiscas del Nuevo Reino de Granada (1537-1650). In: F. Alzate, C. Valencia, (Eds.). Imperios ibéricos en comarcas americanas: estudios regionales de la historia colonial brasilera e neogranadina. Bogotá, Editorial Universidad del Rosario: 136-164.

GASSÓN, R. 1998. Prehispanic intensive agriculture, settlement pattern and Political economy in the western venezuelan llanos. 1998. Tese de Doutoramento, University of Pittsburgh.

Groot, A. M. 1992. Checua: una secuencia cultural entre 8500 y 3000 años antes del presente. Bogotá, FIAN -Banco de la República.

Gutierrez, S.; GARCíA, L. 1983. Vacio prehistórico en la Sabana de Bogotá". Bogotá, ICAN.

Gutierrez, S.; GARCÍA, L. 1985. Arqueología de Rescate, Funza III. Bogotá, ICAN.

Hammond, N. 1984. Raised-Field Farming in Mesoamerica. Science, 224 (4650): 741-743

KRUSCHEK, M. 2003. The evolution of the Bogota Chiefdom: a household view. 2003. Tese de Doutoramento, University of Pittsburgh.
LANGEBAEK, C. 1985. Mercados y circulación de productos en el altiplano cundiboyacense: contribución al estudio de la economía, poblamiento $y$ organización social Muisca. Bogotá, Universidad de los Andes.

LANGEBAEK, C. 2012. Vivir y morir en Tibanica: reflexiones sobre el poder político en una comunidad muisca de la Sabana de Bogotá. Bogotá, ICANH.

LLERAS, R. 2000. La orfebrería y los Cacicazgos Muiscas: los problemas del material arqueológico y las etnias. Sabana de Bogotá. In: B. ENCISO, M THERRIEN, (Eds.). Sociedades complejas en la Sabana de Bogotá, siglos VIII al XVI D.C. Tomo III. Bogotá, ICANH: 77-92.

Moreno L.; Cifuentes, A. 1987. Proyecto de Arqueología de Rescate de la Avenida Villavicencio (Candelaria la Nueva). Bogotá, ICAN.

ORRANTÍA, J. C. 1997. Potreroalto: informe preliminar sobre un sitio temprano en la Sabana de Bogotá. Revista de Antropología y Arqueología, 9 (1-2):181-184

PARCAK, S. 2009. Satellite Remote Sensing for archaeology. London, Routledge.

PARSONS, J. 1969. Ridged Fields in the Rio Guayas Valley, Ecuador. American Antiquity, 34 (1): 76-80.

PARsons, J.; Bowen, W. 1966. Ancient ridged fields of the San Jorge river floodplain, Colombia. The Geographical Review, 56: 317-143.

PÉReZ Preciado, A. 2000. La estructura ecológica principal de la Sabana de Bogotá. Bogotá, Sociedad Geográfica de Colombia.

Plazas C.; FAlChETti A. 1986. Reconstrucción del sistema hidráulico Zenú. Bogotá, ICAN

Plazas C.; Falchetti A.; SÁenZ J. \& ArChila S. 1993. La sociedad hidráulica Zenú: estudio arqueológico de 2000 años de historia en las llanuras del Caribe colombiano. Bogotá, Museo del Oro-Banco de la República.

RoDRÍGUEZ CUENCA, J. V. 1999. Los chibchas: pobladores antiguos de los Andes orientales: adaptaciones bioculturales. Santafé de Bogotá, FIAN.

Rodriguez Gallo, L. 2011. Cultivos de agua. La experiencia prehispánica en la Sabana de Bogotá Sistema de camellones en el valle de los ríos Tunjuelito y Bogotá. Editorial Académica Española.

Rodriguez GALlo, L. 2015. Água e paisagem agrícola entre os grupos pré-hispânicos da Sabana de Bogotá - Colômbia. Tese de doutoramento, Universidade de São Paulo.Disponivel em: http:// www.teses.usp.br/teses/disponiveis/71/71131/tde06082015-144204/pt-br.php

Romano, F. 2003. San Carlos: Documentando trayectorias evolutivas de la organización social de unidades domésticas en un cacicazgo de la Sabana de Bogotá. (Funza, Cundinamarca). Boletín de arqueología, 18 3-51.

Silva Celis, E. 1943. Arqueologia Chibcha Investigaciones en Soacha, Panamá. Bogotá, ICANH.

SchaAn, D. 2012. Sacred geographies of ancient Amazonia. Historical ecology of social complexity. California, Left Coast Press. 
VALDEZ, F. (Ed.). 2006. Agricultura ancestral. Camellones y albarradas: Contexto social, usos y retos del pasado y del presente. Quito: Abya-Yala.

VAN DER HAMmEN, T. (Ed.). 1992. Historia, ecología y vegetación. Bogotá, Banco Popular-COA.
VAN DER HAMmen, T. 2003. Los humedales de la Sabana. Origen, evolución, degradación y restauración. In: Los humedales de Bogotá y la Sabana. Bogotá, Empresa de Acueducto y Alcantarillado de Bogotá: 19-48. 
ANEXO 1: Datações de C14 para a Sabana de Bogotá

\begin{tabular}{|c|c|c|c|c|c|}
\hline No. Laboratório & Fecha C14 BP & $\begin{array}{c}\text { Fecha calibrada } \\
\text { C14 BP (sigma 2) }\end{array}$ & $\begin{array}{c}\text { Fecha C14 } \\
\text { AC / DC }\end{array}$ & Local & Fonte \\
\hline GrN 5556, Col 85 & $12400 \pm 160$ & $14626 \pm 414$ & $12676 \pm 414 \mathrm{AC}$ & Abra & CORREAL et al., 1969 \\
\hline GrN 6505 & $10590 \pm 260$ & $12365 \pm 361$ & $10415 \pm 361 \mathrm{AC}$ & Tequendama & $\begin{array}{c}\text { CORREAL Y VAN DER HAM- } \\
\text { MEN, } 1977\end{array}$ \\
\hline GrN 6732 & $10130 \pm 150$ & $11768 \pm 312$ & $9818 \pm 312 \mathrm{AC}$ & Tequendama & $\begin{array}{c}\text { CORREAL Y VAN DER HAM- } \\
\text { MEN, } 1977\end{array}$ \\
\hline GrN 5561, Col 83 & $9340 \pm 90$ & $10543 \pm 127$ & $8593 \pm 127 \mathrm{AC}$ & Abra & CORREAL et al., 1969 \\
\hline GrN 16346 & $8740 \pm 60$ & $9746 \pm 118$ & $7796 \pm 118 \mathrm{AC}$ & Galindo & PINTO, 2003 \\
\hline GrN5710, Col 82 & $8670 \pm 400$ & $9725 \pm 496$ & $7775 \pm 496 \mathrm{AC}$ & Abra & CORREAL et al., 1969 \\
\hline Beta 53925 & $8200 \pm 110$ & $9188 \pm 146$ & $7238 \pm 146 \mathrm{AC}$ & Checua & GROOT, 1992 \\
\hline Beta 53924 & $7800 \pm 160$ & $8683 \pm 212$ & $6733 \pm 212 \mathrm{AC}$ & Checua & GROOT, 1992 \\
\hline GrN 14477, Col 1592 & $5025 \pm 40$ & $5790 \pm 76$ & $3840 \pm 76 \mathrm{AC}$ & Aguazuque & CORREAL, 1990 \\
\hline GrN 12930, Col 477 & $4030 \pm 35$ & $4502 \pm 48$ & $2552 \pm 48 \mathrm{AC}$ & Aguazuque & CORREAL, 1990 \\
\hline GrN 14478, Col 593 & $3850 \pm 35$ & $4283 \pm 82$ & $2333 \pm 82 \mathrm{AC}$ & Aguazuque & CORREAL, 1990 \\
\hline GrN-11125 & $3270 \pm 30$ & $3507 \pm 42$ & $1557 \pm 42 \mathrm{AC}$ & Zipacón & CORREAL Y PINTO, 1983 \\
\hline GrN 12929, Col 476 & $3140 \pm 35$ & $3375 \pm 30$ & $1425 \pm 30 \mathrm{AC}$ & Vistahermosa & CORREAL, 1987 \\
\hline GrN 12928, Col 475 & $3135 \pm 35$ & $3366 \pm 32$ & $1416 \pm 32 \mathrm{AC}$ & Vistahermosa & CORREAL, 1987 \\
\hline GX - 30239 & $3050 \pm 40$ & $3276 \pm 54$ & $1326 \pm 54 \mathrm{AC}$ & Guaymaral & BOADA, 2006 \\
\hline Beta 20951 & $2750 \pm 100$ & $2897 \pm 108$ & $947 \pm 108 \mathrm{AC}$ & Tocarema & PEÑA, 1991 \\
\hline GX - 30234 & $2450 \pm 40$ & $2538 \pm 125$ & $588 \pm 125 \mathrm{AC}$ & La Filomena & BOADA, 2006 \\
\hline GrN-6536 & $2225 \pm 65$ & $2234 \pm 76$ & $284 \pm 76 \mathrm{AC}$ & Tequendama & $\begin{array}{c}\text { CORREAL Y VAN DER HAM- } \\
\text { MEN, } 1977\end{array}$ \\
\hline GrN 6544 & $2210 \pm 65$ & $2223 \pm 80$ & $273 \pm 80 \mathrm{AC}$ & Nemocón & CARDALE, 1981 \\
\hline GrN 8452 & $2100 \pm 60$ & $2088 \pm 80$ & $138 \pm 80 \mathrm{AC}$ & Zipaquirá & CARDALE, 1981 \\
\hline GrN 6542 & $1975 \pm 60$ & $1935 \pm 63$ & $15 \pm 63 \mathrm{DC}$ & Nemocón & CARDALE, 1981 \\
\hline GrN 8453 & $1955 \pm 40$ & $36 \pm 44$ & $36 \pm 44 \mathrm{DC}$ & Zipaquirá & CARDALE, 1981 \\
\hline GrN 8454 & $1920 \pm 35$ & $1873 \pm 37$ & $77 \pm 37 \mathrm{DC}$ & Zipaquirá & CARDALE, 1981 \\
\hline GrN 9240 & $1890 \pm 50$ & $1825 \pm 62$ & $125 \pm 62 \mathrm{DC}$ & Zipaquirá & CARDALE, 1981 \\
\hline GrN 15742 & $1820 \pm 80$ & $1746 \pm 99$ & $204 \pm 99 \mathrm{DC}$ & Tocarema & PEÑA, 1991 \\
\hline GX - 30235 & $1510 \pm 40$ & $1419 \pm 59$ & $531 \pm 59 \mathrm{DC}$ & La Filomena & BOADA, 2006 \\
\hline GX - 30238 & $1370 \pm 40$ & $1300 \pm 22$ & $650 \pm 22 \mathrm{DC}$ & Guaymaral & BOADA, 2006 \\
\hline Beta 176592 & $1230 \pm 70$ & $1160 \pm 82$ & $790 \pm 82 \mathrm{DC}$ & San Carlos & ROMANO, 2003 \\
\hline Beta 176594 & $1190 \pm 40$ & $1121 \pm 51$ & $829 \pm 51 \mathrm{DC}$ & San Carlos & ROMANO, 2003 \\
\hline Beta 176593 & $1010 \pm 60$ & $910 \pm 71$ & $1040 \pm 71 \mathrm{DC}$ & San Carlos & ROMANO, 2003 \\
\hline
\end{tabular}

\section{ANEXO 2: Fotografia aérea}

Envelope 401, voo A-27. Escala 1: 24.000. Setembro de 1938, IGAC Envelope 402, voo A-27. Escala 1: 24.000. Setembro de 1938, IGAC Envelope 843, voo C-35. Escala 1: 22.000. Março de 1940, IGAC Envelope 844, voo C-35. Escala 1: 22.000. Março de 1940, IGAC Envelope 845, voo C-36. Escala 1: 22.000. Março de 1940, IGAC Envelope 2280, voo C-525. Escala 1: 20.000. Dezembro de 1949, IGAC Envelope 2281, voo C-525. Escala 1: 20.000. Dezembro de 1949, IGAC Envelope 2282, voo C-525. Escala 1: 20.000. Dezembro de 1949, IGAC Envelope 2283, voo C-525. Escala 1: 20.000. Dezembro de 1949, IGAC Envelope 2376, voo C-549. Escala 1: 25.000. Junho de 1950, IGAC Envelope 2380, voo C-550. Escala 1: 10.000. Junho de 1950, IGAC Envelope 2382, voo C-550. Escala 1: 10.000. Junho de 1950, IGAC Envelope 2704, voo C-604. Escala 1: 15.000. Outubro de 1951, IGAC Envelope 2711, voo C-105. Escala 1: 20.000. Outubro de 1951, IGAC Envelope 2712, voo C-605. Escala 1: 20.000. Outubro de 1951, IGAC Envelope 2720, voo C-606. Escala 1: 20.000. Dezembro de 1951, IGAC Envelope 2721, voo C-606. Escala 1: 20.000. Outubro de 1951, IGAC Envelopes: de 20015 a 20022, voo C-619. Escala 1: 18.000. Março de 1952, IGAC Envelope 20024, voo C-620. Escala 1: 18.000. Março de 1952, IGAC Envelope 10420, voo B-99. Escala 1: 4.000. Setembro de 1952, IGAC Envelope 10425, voo B-100. Escala 1: 4.000. Setembro de 1952, IGAC Envelopes: de 2850 a 2854, voo C-742. Escala 1: 9.000. Janeiro de 1955, IGAC Envelope 2856, voo C-742. Escala 1: 9.000. Janeiro de 1955, IGAC Envelopes: de 2873 a 2879, voo C-754. Escala 1:9.000. Junho de 1955, IGAC Envelope 20874, voo C-758. Escala 1: 7.000. Novembro de 1955, IGAC Envelope 20876, voo C-758. Escala 1: 7.000. Novembro de 1955, IGAC Envelope 2913, voo C-769. Escala 1: 9.000. Janeiro de 1956, IGAC Envelope 2927, voo C-770. Escala 1: 9.000. Janeiro de 1956, IGAC Envelope 2935, voo C-772. Escala 1: 9.000. Fevereiro de 1956, IGAC Envelopes: de 2940 a 2946, voo C-773. Escala 1: 9.000. Fevereiro de 1956, IGAC Envelope 2962, voo C-778. Escala 1: 3.000. Maio de 1956, IGAC Envelope 20998, voo C-790. Escala 1: 13.000. Novembro de 1956, IGAC Envelope 20999, voo C-790. Escala 1: 13.000. Novembro de 1956, IGAC *Instituto Geográfico Agustín Codazzi 